\title{
Variações locais na implementação de políticas públicas de educação integral: estudo de casos de duas escolas da rede pública estadual do município de Patos de Minas/MG
}

Local variations in the implementation of public policies of full-time education: case studies in two schools of the public state network of the municipality of

Patos de Minas/mg

Variaciones locales en la implementación de políticas públicas de educación integral: estudio de casos de dos escuelas de la red pública estatal del municipio de Patos de Minas/MG

LORENA ALVES DE OLIVEIRA MARILENE DE SOUZA CAMPOS

Resumo: Este estudo de caso duplo teve por objetivo avaliar se a implementação da política pública da escola em tempo integral em duas escolas da rede pública estadual de Patos de Minas/MG produziu variações em relação ao modelo previsto nas normas estaduais. Combinou-se a pesquisa bibliográfica e documental, observação participante e entrevistas semiestruturadas. Realizou-se análise temática de conteúdo de 16 entrevistas, por meio do Programa Atlas TI 7.0. A normativa prevista é implementada parcialmente por falta de recursos materiais, financeiros, humanos, espaço físico e interesse da comunidade.

Palavras-chave: Política pública. Educação integral. Variações.

Abstract: This double case study aimed to evaluate whether the implementation of the public policy of full-time school in two schools of Patos de MinasMG, produced variations in relation to the model provided in the state norms. Bibliographic and documentary research, participant observation and semistructured interviews were combined. Thematic content analysis of 16 interviews was conducted through the Atlas TI 7.0 Program. The envisaged policy is partially implemented due to lack of material, financial, human resources, physical space, and community interest..

Keywords: Public policy. Full-time education. Variations. 
Resumen: Este estudio de caso doble tuvo como objetivo evaluar si la implementación de la política pública de la escuela en tiempo completo en dos escuelas de la red pública estatal de Patos de Minas / MG produjo variaciones en relación con el modelo previsto en las normas estatales. Se combinaron investigaciones bibliográficas y documentales, observación participante y entrevistas semiestructuradas. Se realizo el análisis de contenido temático de 16 entrevistas, a través del programa Atlas TI 7.0. La norma prevista se implementa parcialmente debido a la falta de material, recursos financieros, humanos, espacio físico e interés de la comunidad.

Palabras clave: Política pública. Educación completa. Variaciones.

\section{INTRODUÇÃO}

As experiências relativas à educação integral no Brasil tiveram origem nas experiências das Escolas-Parque e Escolas-Classe de Anísio Teixeira, nos anos 1940 e 1960, e nos Centros Integrados de Educação Pública (CIEPs) de Darcy Ribeiro, nos anos 1980 e 1990. O objetivo desses autores era promover a democratização do acesso à educação, com a inclusão dos alunos originários das classes sociais mais baixas. Naquela época, a escola em tempo integral já era concebida como direito e ofertada como política pública em escolas nas quais eram oportunizados, além dos espaços para as atividades escolares básicas, espaços amplos para o ensino de artes plásticas, dança, teatro, bibliotecas, áreas esportivas, refeitórios, apoio escolar, dentre outras atividades (TEIXEIRA, 1994; 1997; RIBEIRO, 1986).

Entendendo-se a educação integral como política pública de caráter inclusivo, destacamos o caráter pouco consensual na literatura da definição de política pública (SOUZA, 2003). O termo pode ser compreendido sob a ótica de quem a formula e como formula e quem a implementa e como a implementa. As duas definições mais simplificadas e conhecidas afirmam que política pública é "o que o governo escolhe ou não fazer" (DYE, 1984) e a resume nas questões "quem ganha o que, quando e como?" (LASWELL, 1984). Nesse contexto, desde o momento em que é formulada até o momento em que é implementada, o governo interage com diversos atores sociais. Um fator bastante constatado é que a maioria dos estudos sobre política pública são voltados para a fase de avaliação, deixando de enfatizar a fase da implementação. Tal fase é envolvida por uma verdadeira dinâmica, influenciada pelos diversos atores que, ao interagirem, influenciam diretamente a maneira como uma política pública será realizada.

O resultado disso é que a política, muitas vezes, pode se distanciar da diretriz que foi proposta inicialmente pelos formuladores, sendo incrementada, descaracterizada ou renovada (ARRETCHE, 2001). Assim, pode se diferenciar do modelo previsto em suas normas e acabar se adequando à especificidade do 
contexto socioeconômico e cultural em que atua. Por essa razão, o processo de implementação de políticas públicas deve ser melhor estudado, tendo em vista a vitalidade que introduz no ciclo das políticas públicas. Atualmente, nos estudos sobre implementação de políticas predomina o modelo top-down, desconsiderando a discricionariedade dos implementadores e sua influência nos resultados da política. Porém, o modelo bottom-up é o mais indicado para se observar tal fase, pois considera que os implementadores exercem tamanha influência nessa fase que acabam por refazerem, eles próprios, a política pública propriamente dita. Outro ponto que deve ser destacado é que a implementação pode ser analisada a partir de três modelos: modelo de controle; modelo de interação; e modelo de cognição. O modelo discutido por este trabalho é o que enfatiza a interação dos atores, considerando que a implementação resulta de um processo de interação entre a estrutura normativa da política pública e as características dos espaços de execução. É importante destacar que qualquer política pública na passagem da formulação à implementação sofre variações que a redesenham, envolvendo pelo menos três grupos de fatores: interpretação dos implementadores; natureza das relações sociais entre os implementadores envolvidos; contextos socioeconômicos e culturais de implementação (ARRETCHE, 2001).

Dessa forma, este estudo se justifica na medida em que abre um leque para as discussões sobre a análise da implementação de políticas públicas sob uma ótica mais dinâmica: aquela que considera a influência tanto dos implementadores, quanto dos espaços de execução sob o resultado dessa política. Assim, o objetivo desse estudo foi avaliar se a implementação da política pública da escola em tempo integral em duas escolas da rede pública estadual de Patos de Minas/ MG produziu variações em relação ao modelo previsto nas normas educacionais estaduais, identificar as variações e verificar se tais variações buscaram maior adequação à especificidade do contexto socioeconômico e cultural. Tal avaliação utilizou como referência o modelo de implementação "bottom-up" e modelo de análise de implementação denominado "modelo de interação".

\section{O CONTEXTO DA EDUCAÇÃO INTEGRAL}

O anseio pela educação integral não se restringe à sociedade brasileira, muito menos é uma aspiração exclusivamente contemporânea. Para se compreender a ideia de educação integral na contemporaneidade é preciso considerar alguns aspectos históricos, entre eles a divisão de classes. É preciso compreender que a forte divisão de classes restringiu o acesso das camadas trabalhadoras às escolas. Desde o princípio, como função social, as instituições escolares foram organizadas para receber os filhos da elite (BECKER, 2015). 
A escola estava voltada para uma criança ideal, não oferecendo um tratamento diferenciado para as crianças pertencentes aos segmentos de baixa renda (PARO et al., 1988). No Brasil, para se compreender a concepção de educação integral é preciso recuar no passado e relembrar o pensamento educacional das décadas de 20 e 30 do século XX. Nessas décadas, diferentes ideologias se entusiasmaram pela educação escolar e a educação integral passou a integrar as propostas das diferentes correntes políticas, tendo como significado a ampliação das tarefas sociais e culturais da classe trabalhadora. Para as correntes autoritárias e elitistas, a educação integral significava a ampliação do controle social e dos processos de distribuição criteriosa dos indivíduos nos segmentos hierarquizados da sociedade. Para as correntes liberais, a educação integral tinha por objetivo a reconstrução das bases sociais para o desenvolvimento democrático (CAVALIERE, 2010). Nas reformas de 1920, a ideia de educação integral esteve associada à alfabetização da massa dos brasileiros, para torná-los cidadãos por meio do acesso à leitura e à escrita. Essa ideia se aprofundou entre os intelectuais reformistas, sendo reforçada pelo Manifesto dos Pioneiros da Educação Nova de 1932. O documento discutia a reconstrução da educação e a organização de um sistema escolar único, laico, público e obrigatório para todos, em que cada um tivesse a oportunidade de se desenvolver integralmente (MANIFESTO DOS PIONEIROS, 1932).

Ao falar sobre a escola de tempo integral, Anísio Teixeira defendia que a escola precisaria fazer as vezes da casa, da família, da classe social e, por fim, da escola propriamente dita, oferecendo à criança oportunidades completas de vida, compreendendo atividades de estudos, de trabalho, de vida social e de recreação e jogos (TEIXEIRA, 1994). Essa socialização se torna ainda mais importante para as crianças das camadas mais pobres da população que não podem contar com alternativas de lazer em ambientes coletivos diversificados. Tais crianças, além da casa, da rua e da escola, não contam com aulas de dança, judô, artes plásticas ou línguas, clube, teatro, cinema e viagens (PARO et al. 1988). Ela representa muito mais do que aulas de reforço ou atendimento individualizado. É uma educação cidadã que vai muito além da educação escolar (MOLL, 2012).

Em um contexto mais recente, em âmbito federal, a estratégia para construção da agenda de educação integral teve início em 2007, por meio do Programa Mais Educação (PME). O PNME foi instituído por meio da Portaria Interministerial $n^{\circ} 17 / 2007$ e regulamentado pelo Decreto 7.083/2010. A proposta era ampliar a jornada escolar para 7 (sete) horas diárias a partir do desenvolvimento de atividades de acompanhamento pedagógico, educação ambiental, esporte e lazer, direitos humanos, cultura e artes, cultura digital, saúde, comunicação e uso de mídias, ciências da natureza e educação econômica. Em 2016, houve uma evolução no Programa e sua substituição pelo Programa Novo Mais Educação (PNME) 
por meio da Portaria MEC no 1.144/2016, sendo regido pela Resolução FNDE $\mathrm{n}^{\circ} 17 / 2017$. Aqui, o objetivo é melhorar a aprendizagem em língua portuguesa e matemática no ensino fundamental, por meio da ampliação da jornada escolar de crianças e adolescentes, mediante a complementação da carga horária de cinco ou quinze horas semanais no turno e contraturno escolar. Conforme o art. $1^{\circ}$, Parágrafo único da Portaria, o Programa é implementado por meio da realização de acompanhamento pedagógico em língua portuguesa e matemática e do desenvolvimento de atividades nos campos de artes, cultura, esporte e lazer, impulsionando a melhoria do desempenho educacional. Sua proposta educativa é trabalhada de forma integrada ao Projeto Político Pedagógico (PPP) da escola, sendo que as escolas possuem autonomia para escolher as atividades que desejam oferecer (DOCUMENTO ORIENTADOR VERSÃO 3 - DOV3, 2017). Para sua execução é necessária a articulação de diversas pessoas dentro da escola, cujo DOPNME chama de atores do programa, sendo eles: articulador da escola, mediador da aprendizagem e facilitador, entre outros atores.

Em Minas Gerais, entre os anos de 2004 e 2006, as escolas iniciaram movimentos de busca pela educação integral, ligados ao Projeto Escola Viva Comunidade Ativa (PEVCA). A partir de 2007, as iniciativas de educação integral estiveram ligadas ao Projeto Escola de Tempo Integral (PROETI). A partir de 2012, o governo de Minas aproximou as iniciativas de educação integral ao Programa Mais Educação do governo federal em relação aos campos de conhecimento trabalhados nas escolas e aos critérios para participar do PROETI. A partir de 2013, passou a fazer parte do PME. Em 2016, aderiu ao PNME, direcionando a implementação do Programa por meio do Documento Orientador do Programa Novo Mais Educação - versão I - 2016 (DOPNME) e do documento intitulado "Caderno de Orientações Pedagógicas" - versão I (COP). Tais documentos foram as bases utilizadas para as análises realizadas nesse trabalho. Em 2017, os trabalhos se operacionalizaram por meio da política pública Educação Integral e Integrada, estabelecida pelo Decreto 47.227/2017. Sua norma orientadora é o Documento Orientador versão 3, emitido no ano de 2017. Em 2019, houve nova atualização do documento orientador, intitulado "Documento Orientador Educação Integral e Integrada Ensino Fundamental”.

\section{A LITERATURA SOBRE POLÍTICAS PÚBLICAS}

De uma maneira bastante simples política pública pode ser definida como uma diretriz elaborada para enfrentar um problema público. É uma orientação ativa ou passiva que possui dois elementos fundamentais: intencionalidade pública e resposta a um problema público. A razão para se estabelecer uma política pública 
é o tratamento ou a resolução de um problema entendido como coletivamente relevante (SECCHI, 2011). Essa definição aponta que o agente primário que atua na produção de política pública (policy-maker) é um governo e que o termo policymaking é um processo de tomada de decisão dinâmico, no qual a maioria das políticas envolve uma série de decisões cumulativas que geram um efeito (outcome) (HOWLETT, RAMESH E PERL, 2013).

No estudo das políticas públicas há duas abordagens: a estadista e a multicêntrica. Enquanto a primeira considera a política pública como monopólio de atores estatais, a segunda considera que as organizações privadas, organizações não governamentais, organismos multilaterais formam redes de políticas públicas que trabalham junto aos atores estatais (SECCHI, 2011). Nessa abordagem, é importante citar o termo burocracia ao nível de rua (street level bureancracy), definindo o grupo de funcionários da estrutura burocrática pública que interage diretamente com o público, influenciando na implementação das políticas públicas. Esses atores fazem as políticas públicas a partir das rotinas que estabelecem e dos dispositivos que inventam para lidar com as incertezas e pressões do trabalho. Isso se dá em decorrência do alto grau de discrição e relativa autonomia em relação à autoridade organizacional (LIPSKY, 1980). A partir daí, a política pública é o resultado da combinação de decisões de diversos agentes. Tais decisões foram tomadas nas fases anteriores do chamado ciclo de políticas públicas, instrumento que permite visualizar a vida de uma política pública (ARRETCHE, 2001).

Uma das formas de lidar com a complexidade do processo de policymaking é dividi-lo em subprocessos, formando um ciclo político (HOWLETT', RAMESH E PERL, 2013) que permite visualizar o processo de elaboração de políticas públicas, mostrando a vida de uma política em fases sequenciais e interdependentes (SECCHI, 2011), sendo formado pelas seguintes fases: montagem da agenda, formulação da política, tomada de decisão, implementação e avaliação. Na implementação há a execução das decisões (LIMA e D'ASCENZI, 2014). Nessa fase, as regras, rotinas e processos sociais são convertidos em ações. $\mathrm{Na}$ implementação, uma política pública pode seguir dois modelos: o modelo topdown (de cima para baixo) ou o modelo bottom-up (de baixo para cima). No modelo top-down há a separação clara entre a tomada de decisão e a implementação. Esse modelo parte do princípio de que a esfera política deve elaborar e decidir as políticas públicas, enquanto a implementação deve ser realizada pela parte administrativa (SECCHI, 2011). Porém, nesse modelo há uma dificuldade para se transmitir a intenção do plano para a linha de comando burocrático (WU et al., 2014). Portanto, é fundamental limitar, regular e controlar a discricionariedade dos implementadores, fornecendo regras claras, compreensíveis e específicas que permitam aos implementadores compreender o que foi proposto no plano (LIMA 
e D’ASCENZI, 2013). Em decorrência disso, o modelo é limitado e seu maior defeito é o pressuposto de que os elaboradores de políticas controlam os processos organizativos, políticos e tecnológicos que condicionam a implementação. A ideia de que quem elabora a política exerce algum tipo de controle direto e determinante sobre a implementação é denominada de "ilustre mentira" da administração pública e dos analistas políticos convencionais. Criticando a visão top down, deve-se comentar que aqueles que elaboram as políticas públicas não exercem o controle decisivo sobre o processo de implementação (ELMORE, 1996).

No que se refere ao modelo bottom-up, há maior liberdade dos burocratas e outros atores em se auto-organizarem e modelarem a implementação de políticas públicas (SECCHI, 2011). Quanto à liberdade dos atores, ela é inevitável e pode ser desejável, pois são eles que conhecem as situações locais e podem adaptar o plano a cada situação (LIPSKY, 1980). Nesse modelo, a implementação é um processo interativo e se concentra nos atores dos níveis organizacionais que executam a implementação (LIMA e D’ASCENZI, 2013). Os defensores desse modelo, também conhecido como modelo "de baixo para cima", ao se depararem com resultados insatisfatórios de políticas públicas, procurarão pelas razões em lacunas de recursos, incentivos embutidos no ambiente institucional e de trabalho, enfrentado pelos burocratas de nível de rua (WU et al., 2014). Ao contrário do modelo top-down, o modelo bottom-up não se inicia com uma declaração de intenção, mas com o comportamento específico de um nível mais baixo no processo de implementação, geralmente, diante da necessidade da política pública (ELMORE, 1996). Assim, os implementadores participam da escolha dos problemas e construção de solução. Dessa forma, o formato adquirido pela política pública pode se modificar durante sua implementação no dia a dia, pois existe maior discricionariedade dos gestores e burocratas. Essa remodelagem não é entendida como um desvirtuamento mas, sim, como uma necessidade daquele que se depara com os problemas práticos de implementação (SECCHI, 2011). A partir daí, é importante observar que a implementação das diversas políticas públicas está sujeita a tal remodelagem. (ELMORE, 1996).

Para se classificar um modelo de implementação em top-down ou bottom-up deve-se observar o nível de discricionariedade exercido pelos implementadores. Cada modelo trabalha com diferentes níveis e possibilidades de autonomia em relação ao plano ou normas que estabelecem os objetivos da política (D'ASCENZI e LIMA, 2011). Assim, no modelo top-down o foco da análise é o processo de formulação, as normas que o estruturam e suas lacunas; enquanto no modelo bottom-up, o foco são os elementos que compõem o contexto no qual a política será implementada, tomando como variáveis as condições dos espaços locais e as 
burocracias implementadoras (LIMA e D'ASCENZI, 2013). Independentemente do modelo que é seguido, é na fase da implementação que a política pública entra em vigor, ou seja, as decisões se traduzem em ações e estratégia (WU et al., 2014).

Considerando que há uma grande distância entre os objetivos e o desenho de programas, é praticamente impossível que ele seja implementado tal como foi previsto, ou seja, não se deve esperar que um programa seja implementado inteiramente de acordo com o que foi previsto por seus formuladores. Essa distância é resultado da cadeia de implementadores envolvidos no processo e do contexto econômico, político e institucional em que operam (DRAIBE, 2001). A distância também pode ser atribuída ao fato de os implementadores não aceitarem os objetivos e regras do programa, discordando de suas prioridades e elegendo suas próprias prioridades como referência para suas ações. Ou ainda, devido às condições institucionais para a implementação de programas poderem variar, levando a adaptações do desenho original (ARRETCHE, 2001). A influência dos implementadores sobre uma política pública é realizada com base nas referências que estes adotam para desempenhar suas funções, visto deterem certa autonomia para determinar a natureza, a quantidade e a qualidade dos bens e serviços a serem oferecidos. Assim, eles têm a prerrogativa de fazer a política conforme seus próprios referenciais. Cada um dos atores age e interage com os demais, influenciando a forma como uma política é implementada (ARRETCHE, 2011).

É importante destacar que existem três modelos de análise da implementação de políticas públicas que estabelecem relação entre a estrutura normativa da política pública e sua implementação, são eles: modelo de controle (valoriza as determinações dispostas na estrutura normativa da política pública e diz respeito às atividades e ações dos indivíduos e das organizações responsáveis por colocar em prática o plano); modelo de interação (a implementação resulta de um processo de interação entre a estrutura normativa da política pública e as características dos espaços de execução); modelo de cognição (a visão de mundo orienta o comportamento dos atores, sendo a implementação um produto de sua ação, o que afeta os resultados e a conformação da política) (LIMA e D'ASCENZI, 2014). O modelo enfatizado por este estudo é o que destaca a interação dos atores. O impacto desse modelo sobre qualquer campo de estudo, sobre política pública é percebido a partir do momento em que se verifica que a interação entre a estrutura normativa de uma política e a especificidade dos espaços onde está sendo executada resulta em diversos formatos de implementação. Tal modelo é estudado, sobretudo, pela autora Arretche, utilizada como base para a análise da implementação da política pública neste trabalho. 
A respeito da legislação e das normas determinadoras de uma política pública, devido às incertezas e contingência que podem surgir, a ação dos implementadores deveria ser pautada nesses dispositivos legais. Eles é que deveriam determinar os objetivos e o desenho de implementação de um programa. Porém, devido à capacidade de informações da agência formuladora, por diversas vezes, os agentes incumbidos da implementação não conhecem de fato o programa, os objetivos e regras efetivamente estabelecidos, levando-os a eleger outra referência para a implementação, que poderá ser seus próprios objetivos ou os objetivos dos stakeholders (ARRETCHE, 2001). A partir de suas ideias, das normas organizacionais formais e informais e do próprio plano que caracteriza a política pública, os atores exercem sua discricionariedade, interpretando e adaptando essa política às circunstâncias locais. Assim, a implementação resulta do processo de interação entre a estrutura normativa da política pública e as características dos espaços de execução. Apesar de o plano já trazer definida a arena na qual o processo deveria ocorrer, o papel dos principais atores envolvidos no plano, as ferramentas e recursos necessários para sua execução, a prática provoca adaptações dos objetivos e das ferramentas de gestão à realidade do espaço local (ARRETCHE, 2011; LIMA e D'ASCENZI, 2013).

No que se refere à implementação de políticas públicas, ela passou a exigir um campo específico de análise a partir do momento em que se verificou que mesmo as políticas mais bem desenhadas não geravam os efeitos desejados (LIMA e D'ASCENZI, 2014). Na literatura isso é explicado como "pontos de estrangulamento alheios à vontade dos implementadores, que implicaram que as metas e os objetivos inicialmente previstos não pudessem ser alcançados" (ARRETCHE, 2001, p. 52), ou seja, algumas especificações podem operar de forma contrária àquela que foi especificada na regulamentação do programa, dadas as condições de incerteza em que foi formulado e aos diversos contextos de implementação.

Assim, no momento da execução de um programa público haverá fortes tendências a não convergência de interesses e concepções ideológicas dos agentes envolvidos, o que impõe incertezas quanto às ações dos implementadores e da perfeita adequação entre a formulação original e a implementação efetiva. Outro fator que impede o ajuste perfeito do desenho de programas é a falta de informações completas e perfeitas acerca da realidade sobre a qual se pretende interferir (ARRETCHE, 2001). No momento da execução de um programa público, os formuladores também se deparam com a complexidade dos fenômenos sociais, que não lhes fornecem condições de prever as contingências que podem afetar a política. A complexidade também se relaciona aos planos e programas que limitam algumas ações e decisões dos agentes, visto que há um 
espaço discricionário aberto aos implementadores. Outra complexidade são as influências políticas que minam a racionalidade técnica dos planos e programas (SILVA e MELO, 2000). Assim, a implementação é observada a partir do plano que deu origem à política. Porém, sua essência é o processo contínuo de adaptação do plano ao contexto. Essa adaptação ocorre até mesmo em programas que contam com rígidos mecanismos de controle (LIMA e D’ASCENZI, 2014).

\section{METODOLOGIA}

Esta pesquisa desenvolveu um estudo de caso duplo, que avaliou se a implementação da política pública de educação em tempo integral nas escolas estaduais Adelaide Maciel e Deiró Eunápio Borges, no município de Patos de Minas, produziu variações em relação ao modelo previsto nas normas educacionais estaduais e, se tais variações buscaram maior adequação à especificidade do contexto socioeconômico e cultural em que estão inseridas. A base epistemológica dos métodos adotados tem origem no estudo de caso duplo que, segundo Yin (2001), é uma investigação empírica de um fenômeno contemporâneo dentro de seu contexto, principalmente quando os limites entre o fenômeno e o contexto não estão claramente definidos. Essa pesquisa qualitativa envolveu uma triangulação metodológica, que combina pesquisa bibliográfica e documental, observação participante e entrevistas semiestruturadas. A abordagem da observação participante apresenta sua fundamentação epistemológica na definição de Malinowski (1990) e Foote-White (1990), na qual o pesquisador permanece na comunidade, observa e coleta informações, utilizando-se de um relato etnográfico e lidando conscientemente com a situação de que a base de dados é obtida em processo interativo que deve ser controlado; a interação o coloca na condição de participante. A entrevista semiestruturada ou por pauta constitui um procedimento no qual o pesquisador realiza perguntas diretamente ao entrevistado, seguindo um roteiro previamente elaborado (GIL, 2012). A pesquisa foi dividida em duas etapas. Na primeira pesquisou-se sobre educação integral, Programa Mais Educação, Programa Novo mais Educação, dispositivos e diretrizes legais que norteiam o Programa. Também foi pesquisado o estado da arte da teorização acerca das políticas públicas e ciclo de políticas públicas, dando ênfase à fase da implementação. Na segunda etapa, foram realizadas entrevistas semiestruturadas ou baseadas em roteiro previamente definido, gravadas com os atores responsáveis pela implementação do PNME nas escolas analisadas: Superintendente Regional de Ensino, Coordenadora do Programa na SRE, diretoras das escolas, professores coordenadores do Projeto, professores orientadores de estudos, professores de oficinas, secretários das escolas e pais de 
crianças que participam do Programa. Foram entrevistadas 16 pessoas, enumeradas de E1 a E16. O período de realização ocorreu entre os dias 12 e 30 de junho de 2018. Após as entrevistas os dados foram analisados utilizando-se o Programa Atlas TI 7.0 para realizar a análise de conteúdo. Desse modo, foram estabelecidas cinco unidades de conteúdo: atividades desenvolvidas na escola; articulação das atividades desenvolvidas com os turnos regulares; mobilização da comunidade para construção e viabilização do PNME; dificuldades na implementação do PNME; e adaptações e inovações necessárias durante a implementação do PNME. As unidades foram subdivididas nas seguintes categorias: rotinas diárias; fatores/ desigualdades sociais; desempenho educacional; habilitação dos articulares para atividades extracurriculares; espaço físico; recursos materiais e financeiros para desenvolver atividades; envolvimento dos pais, familiares, professores. Para realizar a análise tomaram-se por base as disposições normativas contidas no Documento Orientador do Programa Nova Mais Educação - versão I - 2016 (DOPNME), no documento intitulado "Caderno de Orientações Pedagógicas" - versão I (COP), na Portaria MEC no 1.144/2016 e na Resolução FNDE no $17 / 2017$.

\section{ANÁLISE DA IMPLEMENTAÇÃO DA POLÍTICA PÚBLICA DE EDUCAÇÃO INTEGRAL NAS ESCOLAS ESTADUAIS ADELAIDE MACIAL E DEIRÓ EUNÁPIO BORGES}

Para se iniciar a análise é necessário considerar que a implementação de um programa é o resultado da ação de uma cadeia de implementadores que atuam no processo (DRAIBE, 2001), assim, considerando-se que no PNME há a atuação de diversos atores, foi construída a Figura 1, mostrando os principais atores sociais locais que influenciam a implementação do Programa. 


\section{Figura 1 - Atores influenciadores da implementação do PNME.}

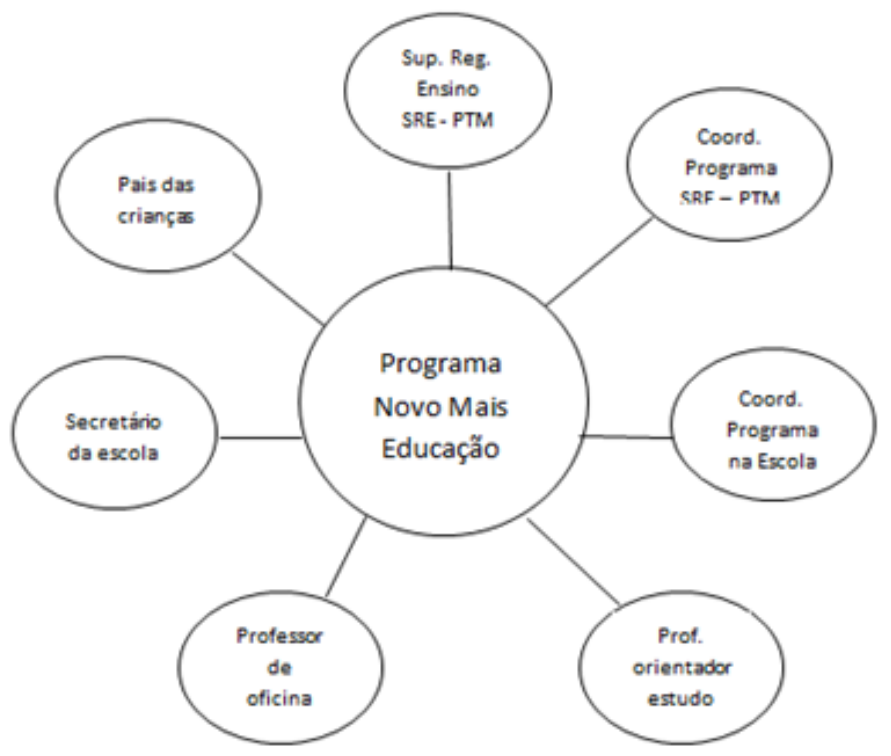

Fonte: Elaborado pela autora.

O desenho da figura, mostrando o PNME no centro das ações de todos os implementadores, recebendo influência de todos eles, parte do modelo de implementação bottom-up, cujo foco são os elementos que compõem o contexto no qual a política é implementada, considerando atores, variáveis e condições locais dos espaços de execução. Esse modelo observa como a política pública está sendo executada, as estratégias utilizadas, os problemas e obstáculos encontrados, observa também como deveria ser e reponde o porquê das desconexões (SECCHI, 2011). Também é preciso considerar que a implementação de uma política pública é resultado do esforço, conhecimento e recursos empregados pelos implementadores para alocar fundos, designar pessoas e desenvolver regras (HOWLET'T, RAMESH E PERL, 2013) e que esses esforços acontecem de maneira diversificada, acabando por remodelar a política, em decorrência da discricionariedade dos implementadores (ARRETCHE, 2001). Assim, foram observadas variações em relação ao modelo previsto para o PNME.

$\mathrm{O}$ fato de as duas escolas estarem inseridas em diferentes regiões do município de Patos de Minas permite inferir que os implementadores dispõem de diferentes realidades para colocar em prática o PNME, tal como espaço físico disponível, parceiros ligados ao trabalho com as crianças, recursos didáticos, etc. Nesse sentido, considerando-se a legislação que trata do PNME, foi observado que nas escolas analisadas o desenho da política pública de educação integral se diferenciou do modelo normativo previsto. 
A primeira e segunda variações observadas partiram da categoria de análise "atividades desenvolvidas nas escolas". A primeira foi identificada na prevalência do pensamento que liga o PNME ao fator social com mais intensidade do que à melhoria de desempenho educacional. Nessa dimensão, ambas as escolas valorizaram mais o cuidado para com o aluno do que a melhoria de seu desempenho escolar. Isso mostra que, na prática, a função da escola de tempo integral ainda segue os princípios de quando foi criada, nos anos 50 e 60. Naquelas décadas, a escola integral era uma alternativa para o cuidado do menor abandonado, oferecendo, primeiramente, assistência social e, posteriormente, educação (PARO et al., 1988). A segunda variação foi relativa à forma de escolha das crianças para participar do PNME. Ambas as escolas deram preferência para as crianças com maior vulnerabilidade social, enquanto as disposições normativas chamaram a atenção primeiramente para aspectos relativos ao desempenho escolar. Observouse que a implementação é o resultado da interação entre a estrutura normativa da política pública e as características dos espaços de execução. Mesmo definindo-se a arena onde o processo deve ocorrer, a prática acaba adaptando os objetivos da política à realidade local (LIMA e D’ASCENZI , 2014).

A terceira, quarta, quinta, sexta e sétima variações partiram da categoria de análise "articulação das atividades desenvolvidas no turno regular com o PNME”. A terceira esteve ligada à articulação das atividades desenvolvidas entre os mediadores e os professores de Língua Portuguesa e Matemática. Nas duas escolas não houve troca de informações entre esses profissionais, os mediadores procuraram as informações de que necessitaram diretamente no caderno dos alunos. Isso mostrou um provável desinteresse dos professores do turno regular em se articular com o Programa. Assim, observou-se que, durante todo o ciclo de uma política pública, pode ocorrer a não convergência de interesses entre os agentes envolvidos na política, resultando em diferenças entre a formulação original de um Programa e sua efetiva implementação (ARRETCHE, 2001). A quarta variação correspondeu ao fato de a legislação exigir pessoal capacitado para desempenhar a função de facilitador, porém, ao mesmo tempo permitir a contratação de pessoas que não possuem formação na área. Esses profissionais, por não conhecerem de fato o objetivo de determinadas oficinas, acabaram por prejudicar as atividades do Programa. Assim, observou-se que os agentes implementadores que não conheciam o programa, objetivos e regras estabelecidas, acabaram elegendo outras referências para a implementação, podendo ser seus próprios objetivos ou os objetivos dos stakeholders (ARRETCHE, 2001). A quinta variação esteve no fato de os articuladores exercerem mais a função de gestores administrativos do que de coordenadores do trabalho pedagógico, dando maior liberdade para os mediadores e facilitares escolherem as atividades que serão 
realizadas, considerando seu próprio planejamento e as demandas das crianças. Esse achado foi o principal ponto que caracterizou essa política pública como pertencente ao modelo de implementação bottom-up. Nesse modelo, o formato da política pública e sua remodelagem resulta da necessidade daquele implementador que se depara com o dia a dia da implementação, seus problemas e necessidades (SECCHI, 2011). Além disso, este modelo de implementação de política pública pode ser conceituado como "modelo de interação" (LIMA e D'ASCENZI , 2014). Tal modelo enfatiza a interação entre os atores e a estrutura normativa do Programa. Seu impacto no campo de estudo foi percebido justamente nas variações que ocorreram no Programa, conforme o contexto socioeconômico e cultural de cada escola.

A sexta variação se relacionou ao planejamento das atividades do Programa. Não havendo participação de professores, estudantes, gestores, pessoas da área administrativa, família e comunidade conforme a normativa. Deve-se destacar que esta variação ocorre de maneira independente à vontade das escolas, visto que, de maneira geral, família e comunidade não procuram participar das atividades do Programa, muito menos de seu planejamento. Nesse sentido, no PNME, há a existência de "pontos de estrangulamento alheios à vontade dos implementadores, que implicaram que as metas e os objetivos inicialmente previstos não pudessem ser alcançados", o que leva o Programa a operar de forma contrária ao especificado em sua regulamentação (ARRETCHE, 2001). A sétima variação foi relativa a não ocorrência de encontros formais entre professores de Língua Portuguesa e Matemática, mediadores e facilitadores do Programa. O objetivo desses encontros é formar mediadores e facilitadores para trabalharem com as crianças do projeto. Apesar de os encontros formais não terem sido citados pelas escolas, foi observado que os profissionais, procuram manter contatos informais entre si compartilhando ideias e conhecimentos. Assim, a implementação também sofreu influência das normas formais e informais que caracterizaram a política pública (LIMA e D’ASCENZI , 2013).

A variação das atividades oferecidas por cada escola não foi considerada como uma variação ao modelo previsto, visto que as duas atenderam às disposições normativas, realizando o acompanhamento pedagógico em Língua Portuguesa e Matemática bem como atividades voltadas para a arte, cultura, esporte e lazer. Também não foi considerada como variação a escolha de locais externos para desenvolver as atividades com as crianças. Tais achados foram considerados como adaptações necessárias à implementação da política pública, em que a liberdade dos burocratas ao se organizar, modela a implementação das políticas (SECCHI, 2011). Isso é desejável, pois são eles que conhecem as situações locais e precisam se adaptar a elas (LIPSKY, 1980). 
Tomando-se por base as variações observadas, é importante propor ações em busca da melhoria das atividades desenvolvidas pelo PNME nessas escolas. As sugestões surgiram a partir da realidade e das manifestações dos agentes envolvidos manifestas nas escolas. Deve-se destacar que tais sugestões não buscaram padronizar o desenho dessa política, mas melhorar as atividades desenvolvidas, utilizando uma visão mais crítica e considerando a atuação dos diversos elementos que a circundam. Assim, seguem as variações observadas e as respectivas propostas:

- Prevalência do fator social em detrimento do desempenho educacional: intensificar as atividades de acompanhamento pedagógico e acompanhar o desempenho das crianças, verificando se houve melhoria ao longo do tempo.

- Modo como as crianças são escolhidas para participar do PNME: consultar o desempenho educacional de cada criança no momento da seleção, priorizando aquelas com baixo desempenho dentro da lista de interessados.

- Falta de articulação das atividades desenvolvidas entre os mediadores e os professores do turno regular: promover reuniões conjuntas entre mediadores e professores do turno regular, buscando compartilhar as atividades planejadas. A partir daí, suas atividades serão passíveis de serem articuladas.

- Dificuldades para a contratação dos facilitadores para trabalhar no PNME: esclarecer, no momento da contratação dos facilitadores, que para o bom desenrolar do PNME é imprescindível que realmente possuam as habilidades apontadas. Destacar suas responsabilidades após o ingresso no PNME.

- Dificuldades para os articuladores desempenharem sua função de forma a atender as normativas: promover reuniões entre os articuladores e mediadores/ facilitadores, buscando informar o PPP da escola e planejar, conjuntamente, as atividades que serão desenvolvidas no PNME. Deve-se destacar que o planejamento não buscará uma rigidez no projeto, mas um melhor panorama das atividades que serão realizadas no decorrer do ano.

- Planejamento das atividades do Programa: divulgar, inclusive entre os pais, que as atividades de planejamento do Programa estão abertas a sugestões. Destacar a importância da participação da comunidade escolar para melhoria do PNME. Realizar o planejamento em finais de semana, facilitando, assim, a participação dos pais.

- Falta de encontros formais entre os professores do turno regular e os atores que implementam o projeto nas escolas: promover reuniões conjuntas entre professores do turno regular e mediadores/facilitadores, buscando trocar experiências e formar pessoal capacitado. 


\section{CONSIDERAÇÕES FINAIS}

Atualmente, busca-se oferecer a educação integral por meio do PNME, sendo expedidas diversas normativas que esclarecem sobre a maneira como tal política deve ser implementada nas escolas. A partir daí, observando-se as normativas e o desenho do PNME nas escolas analisadas, foi verificado, tal como explicado pela literatura que trabalha com o tema da implementação de políticas, que, na prática, houve a modificação dessa política pública, que acabou sendo efetivamente realizada pelos agentes encarregados de sua implementação. Tais agentes implementaram a política a partir de suas próprias referências, adequando suas ações às circunstâncias locais. Assim, neste trabalho observou-se que a política pública de educação em tempo integral implementada nas escolas analisadas se diferenciou do modelo normativo previsto, sendo identificadas diferenças e semelhantes na forma de implementação, de forma a se adequar ao contexto socioeconômico e cultural de cada escola. Algumas mudanças ocorreram de forma intencional do gestor como forma de adequar o projeto à realidade da escola e das crianças. Elas buscaram melhorar o projeto, mesmo diante das limitações que as escolas possuíam.

A partir das variáveis observadas, foi realizada uma proposta de melhoria das práticas nas escolas analisadas. Além disso, este trabalho sugere a realização de pesquisas futuras que busquem verificar o reflexo do Programa sobre a aprendizagem escolar. Deve-se destacar que a implementação do PNME nas escolas, foco deste estudo, atendeu ao modelo bottom-up, visto que houve liberdade das pessoas que estavam na linha de frente do Programa para se organizarem, escolhendo aquilo que melhor atendia a sua realidade durante a implementação da política pública. Além disso, durante esse processo, houve a interação de diversos atores (professores, diretores, coordenadores, alunos, parceiros), que resultou no formato de implementação utilizado em cada escola, ou seja, em cada uma delas, o modelo resultou do comportamento específico dessas pessoas que compunham o nível mais baixo do processo de implementação. 


\section{REFERÊNCIAS}

ARRETCHE, M. T. S. Uma contribuição para fazermos avaliações menos ingênuas. In: BARREIRA, M. C. R. N.; CARVALHO, M. C. B. (Org.). Tendências e perspectivas na avaliação de políticas e programas sociais. São Paulo: IEE/PUC-SP, 2001.

BECKER, P. C. C. Do programa mais educação à educação integral: o currículo como movimento indutor. 2015. 158 f. Dissertação (Mestrado em Educação) - Universidade Federal de Santa Catarina, Centro de Ciências da Educação, 2015. Disponível em: <https://sucupira.capes.gov.br/sucupira/ public/consultas/coleta/trabalhoConclusao/viewTrabalhoConclusao. jsf?popup $=$ true\&id_trabalho $=2542252>$. Acesso em: jul. 2017.

BELO HORIZONTE. Secretaria de Estado de Educação de Minas Gerais. Subsecretaria de Desenvolvimento da Educação Básica. Documento Orientador - Versão 3. Belo Horizonte, 2017, 77 p.

CONSELHO DELIBERATIVO DO FUNDO NACIONAL DE DESENVOLVIMENTO DA EDUCAÇÃO. Resolução n. 5, de 25 de outubro de 2016. Destina recursos financeiros, nos moldes operacionais e regulamentares do Programa Dinheiro Direto na Escola - PDDE, a escolas públicas municipais, estaduais e do Distrito Federal, a fim de contribuir para que estas realizem atividades complementares de acompanhamento pedagógico, em conformidade com o Programa Novo Mais Educação. Diário Oficial da União, Brasilia, DF. 2016.

CAVALCANTE, R. Educação Integral: possibilidades e desafios. 2013. 43 f. Monografia (Especialização em Educação Integral) - Centro de Ciências da Educação, Universidade Federal de Santa Catarina, Florianópolis, 2013. Disponível em: < < L C $\quad$ ttps://repositorio.ufsc.br/bitstream/handle/123456789/105674/ ROSANA\%20CALVACANTE.pdf?sequence=1>. Acesso em: mai. 2017.

CAVAliere, A. M. V. Anísio Teixeira e a educação integral. Paidéia. Rio de Janeiro, UFRJ, v. 20, n. 46, p. 249-259, maio-ago. 2010. Disponível em: <www. scielo.br/pdf/paideia/v20n46/11.pdf>. Acesso em: mar. 2014. 
DRAIBE, S. M. Avaliação de implementação: esboço de uma metodologia de trabalho em políticas públicas. In: BARREIRA, M. C. R. N.; CARVALHO, M. C. B. (Org.). Tendências e perspectivas na avaliação de políticas e programas sociais. São Paulo: IEE/PUC-SP, 2001.

DYE, T. Understanding public policy. Englewood Cliffs, New Jersey, PrenticeHall, 1984.

ELMORE, R. F. Diseño retrospectivo: la investigácion de la implementación y las decisiones políticas. In: VAN METER, D. S.; VAN HORN, C. E.; REIN, M.; RABINOVITZ, F. F. \& ELMORE, R. (dirs.). La implementación de las políticas. México: Miguel Angel Porrua, 1996. Disponível em: < https://pt.scribd. com/document/46233454/4-Elmore-Implementacion-Diseno-Retrospectivo>. Acesso em: ago. 2017.

FOOT-WHYTE, W. Treinando a observação participante. In: ZALUAR, A. Desvendando máscaras sociais. Rio de Janeiro, Francisco Alves Editora, 1999.

GIL, A. Métodos e técnicas de pesquisa social. São Paulo, Atlas, 2012.

HOWletT, M.; RAmeSh, M; PERL, A. Política Pública: seus ciclos e subsistemas: uma abordagem integral. Rio de Janeiro: Elsevier, 2013.

LASWELL, H. Política: quem ganha o que, quando e como. Brasília, Editora Universidade de Brasília, 1984.

LIMA, L. L.; D’ASCENZI. Estrutura normativa e implementação de políticas públicas. In: MADEIRA, L. M. (Org.). Avaliação de políticas públicas. Porto Alegre: UFRGS/CEGOV, 2014.

LIMA, L. L.; D’ASCENZI, L. Implementação de políticas públicas: perspectivas analíticas. Revista de Sociologia e Política, v. 21, n. 48, p. 101-110, dez. 2013. Disponível em: <http://www.scielo.br/scielo.php?script=sci_arttext\&pid= S0104-44782013000400006\&lng=en\&nrm=iso >. Acesso em 23 fev. 2014.

LIPSKY, M. Street-Level Bureaucracy: Dilemmas of the individual in public services. New York: Russel Sage, 1980. 
MALINOWSKI, B. Objeto, método e alcance desta pesquisa. In: ZALUAR, A. Desvendando máscaras sociais. Rio de Janeiro, Francisco Alves Editora, 1999.

MINAS GERAIS. Secretaria de Estado de Educação. Programa estruturador educação para crescer: Projeto estratégico Educação em Tempo Integral: Anexo I e II. Belo Horizonte, SEE/MG, 2013.

MINAS GERAIS. Agência Minas. Disponível em: < http://www.agenciaminas. mg.gov.br/>. Acesso em: ago. 2019.

Ministério da Educação. Portaria no 1.144, de 10 de outubro de 2016. Institui o Programa Novo Mais Educação. Diário Oficial da União. Brasília, DF, 10 out. 2016. Disponível em: <http://portal.mec.gov.br/index.php?option=com_ docman\&view $=$ download \&alias $=49121$ - port-1145-11 out-pdf\&category_ slug=outubro-2016-pdf\&Itemid=30192>. Acesso em: jun. 2017.

MOLL, J. A agenda da educação integral: compromissos para sua consolidação como política pública. In: MOLL, J. et. al. Caminhos da educação integral no Brasil: direito a outros tempos e espaços educativos. Porto Alegre: Penso, 2012.

PARO, V. H.; FERRETI, C. J.; VIANNA, C. P.; SOUZA, D. T. Escola de tempo integral: desafio para o ensino público. São Paulo: Cortez, 1988.

SECCHI, L. Políticas públicas: conceitos, esquemas de análise, casos práticos. São Paulo: Cengage Learning, 2011. 133 p.

SILVA , P. L. B.; MELO , M. A. B. O processo de implementação de políticas públicas no Brasil: características e determinantes da avaliação de programas e projetos. Caderno NEPP/UNICAMP, Campinas, n. 48, p. 1-16. Disponível em: <http://governancaegestao.files.wordpress.com/2008/05/teresa-aula_22. pdf>. Acesso em: 20.set.2013.

SOUZA, C. Políticas públicas: questões temáticas e de pesquisa. Caderno CRH, Salvador, n.39, p 11-24, jul-dez. 2003.

TEIXEIRA, A. Educação não é privilégio. 5. ed. Rio de Janeiro: UFRJ, 1994. $252 \mathrm{p}$. 
TEIXEIRA, A. Educação para a Democracia: introdução a administração educacional. 2. ed. Rio de Janeiro: UFRJ, 1997. 263 p.

TEIXEIRA, A. O manifesto dos pioneiros da educação nova. Revista Brasileira de Estudos Pedagógicos. Brasília, v.65, n.150, maio/ago. 1984. p.407-425. Disponível em: < http://www.bvanisioteixeira.ufba.br/artigos/mapion.htm>. Acesso em: jun. 2017.

WU, X.; RAMESCH, M.; HOWLETT, M.; FRITZEN, S. Guia de Políticas Públicas: Gerenciando Processos. Traduzido por Ricardo Avelar de Souza. Brasília: Enap, 2014. 160 p.

YIN, R. Estudo de caso: planejamento e métodos. São Paulo, Bookman, 2001.

LORENA ALVES DE OLIVEIRA Possui graduação em Administração Pública pela UFOP (2013), pós graduação em Administração Pública pela UFJF (2015) e Mestrado em Administração Pública (2018) pelo Programa de Mestrado Profissional (PROFIAP) da Universidade Federal de Viçosa - Campus Rio Paranaíba. Atualmente é servidora pública da Universidade Federal de Uberlândia - Campus Patos de Minas, trabalhando como secretária do Curso de Graduação em Engenharia Eletrônica e de Telecomunicações - Campus Patos de Minas. E-mail: lorenaalvesdeoliveira@hotmail.com

ORCID: https://orcid.org/0000-0003-3735-4497

MARILENE DE SOUZA CAMPOS Possui graduação em Ciências Sociais pela UFMG(1991), Mestrado (1998) e Doutorado(2003) em Sociologia pelo Instituto Universitário de Pesquisas do Rio de Janeiro(IUPERJ).Realizou parte de sua formação do Doutorado na Università degli Studi di TorinoITA(2001-2002). Atualmente é professora associada da Universidade Federal de Viçosa. Tem experiência na área de Sociologia, com ênfase em sociologia econômica e administração pública, atuando principalmente com as seguintes temáticas:políticas públicas, desenvolvimento local, cidades, e democracia participativa.

E-mail: marilenecrp@gmail.com

ORCID: https://orcid.org/0000-0002-3896-4222 